\title{
Who Dominates the Discourses of the Past? Gender, Occupational Affiliation, and Multivocality in North American Archaeology Publishing
}

\author{
Tiffany J. Fulkerson (1D) and Shannon Tushingham
}

\begin{abstract}
Equity and the dissemination of knowledge remain major challenges in science. Peer-reviewed journal publications are generally the most cited, yet certain groups dominate in archaeology. Such uniformity of voice profoundly limits not only who conveys the past but also what parts of the material record are narrated and/or go untold. This study examines multiple participation metrics in archaeology and explores the intersections of gender and occupational affiliation in peer-reviewed (high time cost) and non-peer-reviewed (reduced time cost) journals. We find that although women and compliance archaeologists remain poorly represented in regional and national peer-reviewed journals, they are much more active in unrefereed publications. We review feminist and theoretical explanations for inequities in science and argue that (1) the persistent underrepresentation of women and of compliance professionals in archaeological publishing are structurally linked processes and (2) such trends can be best understood in light of the existing structure of American archaeology and the cost-benefit realities of publishing for people in various sectors of the discipline. We suggest that nonrefereed venues offer a pathway to multivocality and help to address epistemic injustices, and we discuss methods for widening the current narrow demographic of men and academics who persist in dominating discourses.
\end{abstract}

Keywords: gender, equity, equality, women, publishing, sociopolitics, multivocality, peer review, cultural resource management, academia

La equidad y la difusión del conocimiento siguen siendo grandes desafíos de la ciencia. Las publicaciones de revistas revisadas por pares son generalmente las más citadas, sin embargo, ciertos grupos dominan en arqueología. Esta uniformidad de voz limita profundamente no solo quién transmite el pasado, sino también que partes del registro material se narran y/o no se mencionan. Este estudio examina múltiples métricas de participación en arqueología y explora las intersecciones de género y afiliación ocupacional en revistas revisadas por pares (costo de tiempo alto) y no revisadas por pares (costo de tiempo reducido). Encontramos que aunque las mujeres y arqueólogos por contrato siguen siendo poco representados en revistas arbitradas regionales y nacionales, son mucho más activos en publicaciones no arbitradas. Revisamos explicaciones feministas y teóricas de las inequidades en la ciencia y argumentamos que (1) la representación insuficiente de mujeres y de profesionales por contrato en publicaciones arqueológicas son procesos estructuralmente vinculados y (2) las tendencias se pueden entender mejor a la luz de la estructura existente de la arqueología estadounidense y las realidades de costo-beneficio de la publicación para el público en diversos sectores de la disciplina. Sugerimos que las plataformas no arbitradas ofrezcan un camino hacia la multivocalidad y ayuden a abordar las injusticias epistémicas y discutan métodos para ampliar la estrecha demografía actual de hombres y académicos que persisten en los discursos dominantes.

Palabras clave: género, equidad, igualdad, mujeres, publicación, sociopolítico, multivocalidad, revistas revisadas por pares, gestión de los recursos culturales, academia

Tiffany J. Fulkerson घ Department of Anthropology, Washington State University, P.O. Box 644910, Pullman, WA 99164-4910, USA (tiffany.fulkerson@wsu.edu, corresponding author) https://orcid.org/0000-0002-9553-9548 Shannon Tushingham - Department of Anthropology, Washington State University, P.O. Box 644910, Pullman, WA 99164-4910, USA

American Antiquity 84(3), 2019, pp. 379-399

Copyright $(92019$ by the Society for American Archaeology. This is an Open Access article, distributed under the terms of the Creative Commons Attribution licence (http://creativecommons.org/licenses/by/4.0/), which permits unrestricted re-use, distribution, and reproduction in any medium, provided the original work is properly cited.

doi:10.1017/aaq.2019.35 
$\mathrm{O}$ ver the past 40 years, researchers have taken to task gender equity issues in archaeological practice. Issues including sexual harassment (e.g., Clancy et al. 2014), the relegation of women to domestic and clerical roles in work environments (e.g., Clarke 1993; Gero 1983, 1985), the valorization of masculinity and heteronormativity in fieldwork settings (e.g., Moser 2007), the underrepresentation of women in grant submissions and awards (e.g., Goldstein et al. 2018; Yellen 1983), gender disparities in academic hiring and on editorial boards (e.g., Hutson 1998; Speakman et al. 2018; Stark et al. 1997), and gender inequities in publishing (e.g., Bardolph 2014, 2018; Bardolph and VanDerwarker 2016; Beaudry and White 1994; Colwell-Chanthaphonh 2004; Tushingham et al. 2017; Victor and Beaudry 1992) have all been considered. With respect to the latter, the weight of evidence suggests that while the number of women who are publishing in archaeology journals has improved since the 1960s, women continue to publish disproportionately less than men. A number of explanations have been offered for this phenomenon, but few studies address how gender disparities may intersect with the unique occupational dynamics of modern Americanist archaeology and related disciplinary traditions that guide how written output is disseminated.

Tracking the occupational affiliation of those who publish is critical to understanding how the dissemination of results is influenced by the changing professional landscape of archaeology. This is particularly true in an era when the overwhelming majority of practitioners in the United States are no longer employed in academic settings but, rather, in agency and private-sector cultural resource management (CRM) (Sebastian 2009:7) and in light of data from western North America that suggest that professional contexts influence the publication decisions of authors (Tushingham et al. 2017). Studies of publishing output - a common metric of professional productivity in the sciences-overwhelmingly focus on analyses of peer-reviewed academic publications. Yet few studies acknowledge the stark differences between academic and extra-academic publication strategies in North American archaeology, and there has been little consideration of the representation of genders and occupational affiliations in nonrefereed publishing venues, which are often deemed as less authoritative or inferior due to their lack of peer review.

The objective of this study is to navigate the landscape of publishing in archaeology, with a focus on the intersections of gender and occupational affiliation. We build on the few, yet notable, existing studies on inequities in archaeology publishing by examining the gender and professional affiliation of authors who publish in two general categories of publications: those that tend to be costly in terms of time investment for authors (peer-reviewed journals) and those with reduced time costs (non-peerreviewed venues). We explore these trends with data from a large, longitudinal database of regional (western North America, including Baja California, Mexico) and national (North America) journals. We show, through an analysis of several participation metrics and journal publishing rates, that despite overall high levels of participation in the field, women and compliance (agency and private-sector CRM) archaeologists have substantially lower publication rates in peerreviewed journals. They are, however, better represented in unrefereed venues. We argue that these results may be best understood in light of the existing structure of American archaeology and the cost-benefit realties/dynamics of publishing, where women and compliance archaeologists are overwhelmingly in positions where publishing is a largely unsupported and unrewarded activity and participation in peer-reviewed/high-time-cost publications is particularly challenging. For women, this is critically linked to the "leaky pipeline" effect, and for compliance archaeologists, this is associated with the realities of compliance archaeology jobs.

We frame our analyses within the context of multivocality and consider the limitations that current publishing trends place on not only who conveys the past but also what parts of the material record are being narrated-or conversely, go untold. As such, we turn a critical eye to the narrow demographic of men and academics who, at present, are the most represented in peer-reviewed publications and therefore dominate archaeological narratives of the human past. 


\section{Multivocality and Dominant Discourses}

Critical to the underrepresentation of women and, importantly, people who have largely been excluded or not explicitly considered in equity inquiries (e.g., Indigenous groups, people of color, the dis/abled, LGBTQ+ people) in archaeological practice is the issue of multivocality. Multivocality is a process whereby multiple voices are made available; it serves "as a way of empowering underrepresented groups to present their understandings and interpretations of the archaeological past" (Fawcett et al. 2008:3; see also Hodder 2004). When women and other peripheral groups are underrepresented in the production and/or dissemination of knowledge, either by choice or through institutional barriers, multivocality becomes inhibited. In effect, the "dominant groups dominate discourse" (Kehoe 1992:23).

The prevailing underrepresentation of the voices of women and marginalized peoples can be seen as an injustice within the sphere of epistemology, or what Fricker (2007) and others refer to as "epistemic injustice." Fricker (2007:1) views the conveyance of knowledge as the most basic epistemic practice. It is well understood that in the sciences, peer-reviewed publications are a predominant and prestigious means of knowledge dissemination. We contend that the promotion of multivocality in knowledge dissemination has the power to combat epistemic injustices and improve systemic inequalities in archaeology publishing.

As with women, archaeologists employed in nonacademic professions largely remain on the periphery of representation in peer-reviewed journals (Harlan 2009; Seymour 2010a, 2010b; Tushingham et al. 2017). This condition is pressing considering that today, roughly $90 \%$ of archaeologists are employed in the field of CRM (Sebastian 2009:7). Importantly, this lack of representation in peer-reviewed journals by extra-academic professionals does not necessarily equate to a lack of writing output. Hundreds of thousands of technical reports (or possibly more) have been produced by private-sector and agency CRM professionals (see Anderson 2018:200), part of a rich corpus of materials often referred to as the "gray literature" (see also Fulkerson and Tushingham 2019). For our analysis, however, we point out the obvious, yet critical, point that technical reports are part of the required work responsibilities of compliance professionals, while journal articles and reports are typically not (which, though generally more widely disseminated, often require significant time expenditure outside of work for people in CRM). Under such circumstances, it is particularly challenging for these individuals to publish in journals with the highest time costs (e.g., high-tier peer-reviewed publications), a point we expand upon below.

Just as the inclusion of women and other marginalized groups can facilitate multivocality and reduce epistemic injustices in archaeology publishing, enhancing the visibility of the writing output of compliance professionals can mobilize the voices of nonacademics, who remain underrepresented in peer-reviewed publishing. While the quality and place of gray literature are variable (for a discussion of debates surrounding the issue, see Tushingham et al. 2017), in a discipline so rich in data from such sources, it is important to consider how we might better integrate information and perspectives from extraacademic settings. As Deni J. Seymour notes, gray literature might "not constitute a problem but rather an opportunity for bringing fresh ideas and new perspectives to the discipline, for reporting state-of-the-art research, and engaging a wider pool of participants in more easily accessed formats" (2010a:228). It follows, then, that promoting and legitimizing the voices of marginalized groups, those that remain on the periphery of publishing, and alternative forms of literature is critical for a more multivocal archaeology. Yet graduate students and those who publish in widely disseminated, high-impact archaeology journals are predominately cisgender, heteronormative, and white (Heath-Stout 2017; Peterson's 2016). Thus, those who dominate discourses in archaeology are mostly straight, cisgender, white men who occupy the ivory towers of academia.

Beyond the problematic lack of diverse perspectives in prevailing narratives of the past, it is important to consider how these conditions influence the dissemination of archaeological discoveries and knowledge. When academics, 
who make up a small fraction of archaeology practitioners in the United States, produce the bulk of its influential literature, then it stands to reason that the majority of cultural resources identified by CRM projects and reported on in technical reports or other forms of gray literature remain poorly represented and largely unknown to much of the archaeology community. Consequently, not only do men and academics dominate archaeology discourses, but so do the cultural resources that constitute academic-oriented archaeology. This, in effect, causes CRM archaeology and many of the resources that are attributed to the human past to be ignored or undervalued in peer-reviewed literature.

The undervaluation/underrepresentation of women and compliance archaeologists in peerreviewed publications is in stark contrast to the demographic landscape of archaeology as a whole, where the discipline is rich with women and compliance professionals. An analysis of participation metrics, explored below through a feminist perspective, provides a means for comparing demographic trends throughout various realms of archaeology and demonstrates where along the trajectory of archaeology these demographic disparities emerge.

\section{Sociopolitics, Demographic Landscapes, and the "Leaky Pipeline" of Archaeology}

Feminist concerns for equity in archaeology have frequently been conceived within a sociopolitical framework, wherein critiques of the discipline reveal how imbalances are systemically gendered (e.g., Bardolph 2014; Conkey 2003; Conkey and Spector 1984; Gero 1985; Hutson 2002; Wylie 1992, 1997). Feminist archaeology has been effective in advocating for an epistemic approach that recognizes the existence of sociopolitical factors and contingencies as well as the importance of empirical constraints on the production of knowledge (Conkey 2003:873-874; Wylie 1997:81; see also Wylie 1992). It is within these veins that early considerations of gender inequities in archaeology were conceptualized.

Early inquiries into the representation of women in peer-reviewed publishing demonstrated that throughout the twentieth century, the climate of archaeology had remained "quite chilly" for women, with a lack of gender parity in published articles, reviewer demographics, and citation practices (Beaudry 1994; Beaudry and White 1994; Victor and Beaudry 1992:16-17; see also Hutson 2002). Gender imbalances exist regionally and nationally (Bardolph 2014, 2018; Bardolph and VanDerwarker 2016; Claassen et al. 1999; Tushingham et al. 2017), despite the strong representation of women practitioners in archaeology. Authorship imbalances exist not only in academic journals but also in popular-culture archaeology magazines that communicate our discipline to the public (e.g., Colwell-Chanthaphonh 2004). Numerous studies implicate authorial choice rather than editorial or reviewer biases in these imbalances (see Bardolph 2014; Beaudry and White 1994; Rautman 2012), with evidence suggesting that women are less likely than men to resubmit peer-reviewed manuscripts (Rautman 2012). Women have cited such difficulties as employment in positions that do not prioritize publishing, lack of confidence, administrative and graduate student duties, and teaching/mentorship obligations as limiting factors to writing and publishing (Bardolph and VanDerwarker 2016: Table 6).

The preponderance of data suggests that while these gender imbalances are improving, there is still much work to be done. For example, Bardolph (2014:527) demonstrates that only $24 \%$ of articles from major national archaeology publications and $29 \%$ of articles from regional journals from 1990 to 2013 were lead-authored by women. This is particularly troubling in light of data demonstrating overall high levels of participation by women in other metrics of disciplinary engagement, particularly within graduate programs, societies, registers, and extraacademic professions (see below). When comparing equitable participation trends with the unequal representation of women in higher levels of the discipline, the picture of a "leaky pipeline" begins to emerge.

The leaky pipeline metaphor describes the loss of women throughout various stages of their career, from college through academic tenure (Alper 1993). We extend this definition to include other advanced levels of archaeology, including CRM company ownership, agency program management, and publishing. The leaky pipeline results 
in fewer women at higher levels of their profession and consequently lower rates of pay, even in fields that have high numbers of women participants. It often begins as early as the undergraduate and graduate levels, where women are influenced by a suite of disciplinary and societal conditions (Stark et al. 1997) as well as lifestyle preferences and selected ideologies (see Stone and McKee 2000) that affect their placement and advancement.

Until the late twentieth century, attrition rates of women in higher education translated to lower rates of women entering and occupying the professional workforce (see Kramer and Stark 1988; Zeder 1997a, 1997b). Fortunately, these conditions improved by the late 1980s and 1990s, with archaeology transitioning into a discipline that is now robust with women by many measures of disciplinary engagement. To better understand these dynamics, we compiled data that reflect the overall participation rates of women, including percentage representations of women $\mathrm{PhD}$ graduates in U.S. archaeology and Society for American Archaeology (SAA) membership from 1967 to 2015, as well as Register of Professional Archaeologists (RPA) and Society of Professional Archaeologists (SOPA) registrants for select years from 1976 to 2018 (Figure 1). Formed in 1988, SOPA evolved into the RPA in 1997-1998 (Niquette 2017). The RPA is a particularly good indication of the representation of women among CRM and agency practitioners. Clearly, women's participation rates have grown historically and today account for more than half of all $\mathrm{PhDs}$ earned and are approaching parity among SAA memberships and RPA registrants. These trends parallel membership findings at the regional level, where women now represent half or more of members of the Society for California Archaeology (Tushingham et al. 2017:Figure 2).

Despite these advancements, studies demonstrate that fewer women present papers at professional conferences, including at annual meetings of the SAA (Burkholder 2006) and the Southeastern Archaeological Conference (Bardolph and VanDerwarker, in Bardolph 2014:526; Claassen et al. 1999). At the Society for California Archaeology (SCA) annual meeting, women present fewer papers but more posters, which may speak to gendered differences in research dissemination strategies or confidence in public speaking (Tushingham et al. 2017).

The leaky pipeline of women in archaeology is particularly apparent in academia. The 1994 SAA census revealed that at the time, an increasing proportion of women were being hired in non-tenure-track faculty positions (Zeder 1997b:Figure 9). By the 1990s, women accounted for only $24 \%$ of archaeology faculty in BA-granting institutions and a mere $15 \%$ of faculty among $\mathrm{PhD}$-granting institutions (Stark et al. 1997). Current national trends indicate that across all disciplines, women account for only $37.6 \%$ of all tenured faculty, while the percentage of non-tenure-track women faculty increased from $43.7 \%$ to $52.5 \%$ from 1993 to 2013 (Finkelstein et al. 2016:Table 2). Speakman and others (2018) demonstrate that men continue to be hired for tenure-track jobs in anthropology at disproportionately higher rates than women and that over the last three decades, there has a been a strong hiring bias toward men in archaeology. The greatest gender segregation is found in programs of prestige, which frequently lead to higher-paying, top-tier positions (Weeden et al. 2017:142, 145). These phenomena help to explain why there remains a persistent gender pay gap across faculty ranks (see Chronicle of Higher Education 2016).

There are similar disadvantages for women in certain aspects of compliance archaeology. Zeder (1997a:189) observed that by the 1990s, there was overall greater gender parity in private-sector employment compared with academia, yet CEOs of larger firms tended to be predominately male. A similar observation was made by Surface-Evans and Jackson (2012:19), who suggest that women are less likely to hold "masculine" positions of leadership in CRM based on their analysis of the American Anthropological Association's Anthro Guide 2010-2011. In terms of financial compensation, a 2005 salary survey points to a mean salary gap ranging from $11.2 \%$ to $13.7 \%$ between women and men in CRM (Association Research 2005:c-3).

Taken together, navigating the demographic landscape of North American archaeology points to persistent attrition of women at the higher 


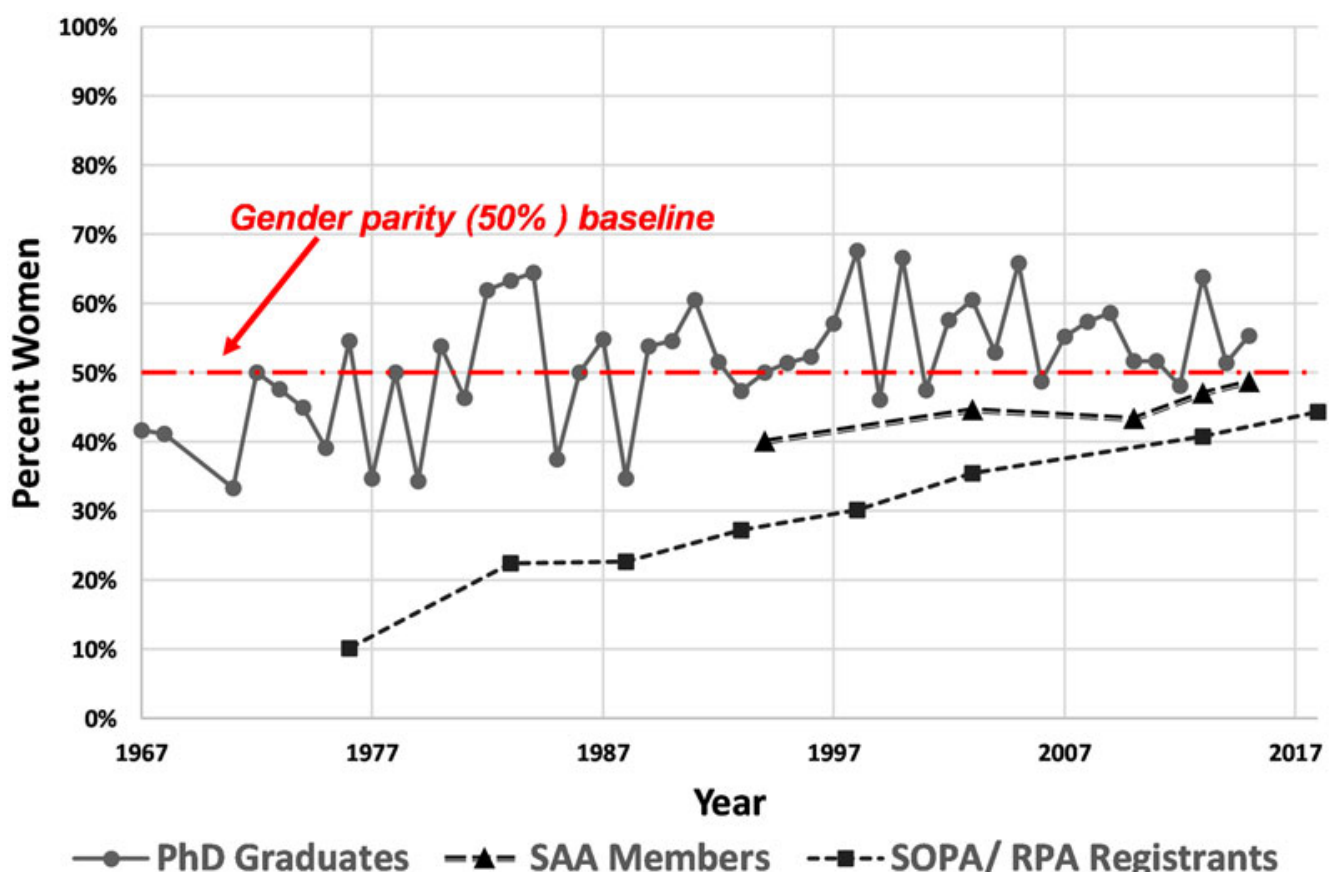

Figure 1. Annual percentage representation of women PhD graduates, Register of Professional Archaeologists (RPA) and Society of Professional Archaeologists (SOPA) members/registrants, and Society for American Archaeology (SAA) members in the United States from as early as 1967 to 2018.

ranks of what is an otherwise "female-rich" discipline. Recently, some have suggested abandoning the leaky pipeline metaphor because it portrays tenure and tenure-track faculty positions as the ultimate form of achievement and devalues the lifestyle choices and contributions of women in nonacademic settings (Miller and Wai 2015). We agree with much of this and strongly believe that our discipline should not be conceived as a unilinear trajectory, with tenured placement at top-tier/R1 universities as the pinnacle of professional success. However, within the context of this study, the leaky pipeline metaphor can be extended to compliance archaeology and is an effective means of evaluating the decreasing proportions of women at higher stages of academic and professional advancement (see also VanDerwarker et al. 2018). We argue that the leaky pipeline is relevant because it is intimately tied to lowered publication rates for women, precisely because women tend to have fewer positions with the time, rewards, and support to actively engage with time-consuming publications.
While women continue to occupy marginalized positions within our discipline, it would be an oversimplification to view them as a monolithic group. Many of the imbalances described here are disproportionately felt by women of color and trans and queer women-people who exist outside of the white, heterosexual, and middle-class demographics that constitute the vast majority of women practitioners (Wylie 1997:82). Investigations into the intersections of publishing with race/ethnicity and LGBTQ+ identities have not been fully actualized. Exploration of these issues requires self-reporting, which is beyond the scope of this study; but fortunately, researchers (e.g., Heath-Stout 2017; Radde 2018) are beginning to address these concerns, and hopefully the future will hold a more inclusive perspective on equity issues in archaeology. With this study, we aim to advance intersectional inquiries into equity in North American archaeology publishing by exploring both gender (specifically women and men) and professional identity, which are components of status and identity that collectively affect all archaeologists. 


\section{Materials and Methods}

In this study, we examine cross-sectional and longitudinal publishing trajectories in professional archaeology journals in three regional and three national venues from the years 2000 to 2017. We selected venues that are roughly comparable in terms of their accessibility, format, and length, focusing on journals that publish articles and reports, which tend to be more widely disseminated (and easier to analyze) than long-form monographs, books, and reports. We then divided these publications into two general categories that vary in terms of time investment: those that tend to be costly in terms of time expenditure for authors (peer-reviewed publications) and those with reduced time costs (non-peer-reviewed publications). While we recognize variability within and between journals/ editors, this division is based on the fact that the peer-review process can be extremely laborintensive, requiring significant time and work to ferry an article through a system that might involve several rounds of revisions and resubmittals to different journals.

We compiled data on the gender and occupational affiliation of lead (first and single) authors, in addition to the gender of secondary/junior authors (referred to here as coauthors), in the peer-reviewed/high-time-cost journals American Antiquity (AQ), Advances in Archaeological Practice (AAP), Journal of California and Great Basin Anthropology (JCGBA), and California Archaeology (CA) as well as the non-peer-reviewed/reduced-time-cost venues the SAA Archaeological Record (SAA Record) and the SCA Proceedings (Table 1). A summary of the history and scope of these journals is included in Supplemental Text 1.

In total, data for 5,010 authors of 2,445 articles were compiled and analyzed. We limited analysis to specific categories of authored pieces for each journal (Supplemental Text 2). Primary and secondary authors were placed into the gender categories of "women," "men," and "unknown/ other" following standard methods detailed in Supplemental Text 3. The gender composition of RPA/SOPA registrants in Figure 1 was determined using similar methods. While we made a good faith effort to avoid improper gender attribution by taking measures including searching for gender pronouns used by authors to describe themselves (see Supplemental Text 3 ), we acknowledge that without self-reporting it is possible to introduce bias, and gender expression does not always accord with gender identity.

To calculate the gender ratios of first/single authors for each journal, we summed the total number of articles lead-authored by women, men, and unknown/other genders individually for each year and divided each sum by the total number of articles per year. To calculate the annual ratios of women to men for each journal, we divided the total number of women first/ single authors by the total number of men first/ single authors. To assess the gender representation of coauthors, we individually summed the total number of women, men, and unknown/ other authors for each year and divided each sum by the total number of coauthors. Percentages were rounded to the nearest tenth for reporting.

The occupational affiliation of each lead author was determined using the author's affiliation(s) as stated in journal article bylines. Affiliations were divided into 10 categories: Academic, Academic Museum, Academic CRM, Museum, Agency, Private Sector/CRM, Tribe, Research Institute, Independent, and Other (Supplemental Text 4). To calculate occupational affiliation ratios, we assigned a numerical value of 1.00 for each affiliation that was represented by lead authors. In cases where a lead author provided more than one affiliation, we divided 1.00 by the total number of affiliations and assigned that fraction to each represented affiliation category. We then summed each category and divided the individual sums by the total number of affiliations for women and men in order to determine their percentage representations.

\section{Results}

\section{Gender Publishing Patterns}

There is a considerable dearth of women authors in the regional and national peer-reviewed/ high-time-cost journals we reviewed over the 18-year period of study (2000-2017) (Table 2; Supplemental Table 1). Among the regional 
Table 1. Journal Summary Data.

\begin{tabular}{llll}
\hline Journal Name & Periodicity & Peer-Reviewed? & Review Method \\
\hline Peer-Reviewed/High-Time-Cost Journals & & & \\
American Antiquity & Quarterly & Yes & Single blind \\
Advances in Archaeological Practice & Quarterly & Yes & Double blind \\
Journal of California and Great Basin Anthropology & Biannually & Yes & Single blind $^{\text {a }}$ \\
California Archaeology & Biannually & Yes & Single blind \\
Non-Peer-Reviewed/Reduced-Time-Cost Journals & & & N/A \\
SAA Record & $5 \times /$ year & No & N/A \\
Society for California Archaeology Proceedings & Annually & No & \\
\hline
\end{tabular}

${ }^{a}$ The Journal of California and Great Basin Anthropology transitioned to a double-blind peer-review process after the period of analysis for this study (see Supplemental Text 1).

(western North America) peer-reviewed journals (JCGBA, CA), women account for an average of only $27.1 \%$ (JCGBA, $n=67 ; C A, n=24)$ of first/single authors compared with men, who make up an average of $72.9 \%$ (JCGBA, $n=$ $166 ; C A, n=70$ ) of first/single authors. In contrast, the non-peer-reviewed/reduced-time-cost SCA Proceedings has a much more equitable publication record, with women accounting for $40.8 \%(n=211)$ of lead authors and $39.5 \%$ ( $n=140$ ) of coauthors for 517 articles. Longitudinal trends (Figure 2) indicate that Proceedings reached or exceeded perfect gender parity $(50 \%$ authorship) in five years between 2009 and 2015; the only other journal to reach that threshold was $C A$ (once, in 2017). Overall, Proceedings has consistently exhibited the greatest representation of women lead authors, while $C A$ has exhibited the least. Notably, representation has improved over time. A previous study demonstrated that the proportion of women lead authors in JCGBA and the SCA Proceedings significantly increased from 1974 to 2016 $\left(p<.01\right.$, by the Cochran-Armitage $\chi^{2}$ test for trend) (Tushingham et al. 2017:Figure 6). However, a publication gap clearly persists in these journals.

On the national front, there is marked variability in women versus men first/single authors, particularly in the peer-reviewed $A A P$ and $A Q$. Whereas

Table 2. Summary Statistics for Women and Men Authors by Journal.

\begin{tabular}{|c|c|c|c|c|c|c|c|c|c|c|c|c|c|c|}
\hline \multirow[b]{2}{*}{ Journal } & \multicolumn{3}{|c|}{$\begin{array}{l}\text { Women First/ } \\
\text { Single Authors }\end{array}$} & \multicolumn{3}{|c|}{$\begin{array}{c}\text { Men First/Single } \\
\text { Authors }\end{array}$} & \multirow{2}{*}{$\begin{array}{l}\text { Mean } \\
\text { W:M } \\
\text { Ratio }\end{array}$} & \multirow{2}{*}{$\begin{array}{c}\text { Total No. } \\
\text { Articles }\end{array}$} & \multicolumn{3}{|c|}{$\begin{array}{l}\text { Women } \\
\text { Coauthors }\end{array}$} & \multicolumn{3}{|c|}{ Men Coauthors } \\
\hline & $n$ & Mean & $\%$ & $n$ & Mean & $\%$ & & & $n$ & Mean & $\%$ & $n$ & Mean & $\%$ \\
\hline \multicolumn{15}{|c|}{ Peer-Reviewed/High-Time-Cost Journals } \\
\hline American Antiquity & 199 & 11.1 & 26.6 & 549 & 30.5 & 73.4 & 0.368 & 748 & 240 & 13.33 & 24.4 & 741 & 41.7 & 75.2 \\
\hline $\begin{array}{l}\text { Advances in } \\
\quad \text { Archaeological } \\
\quad \text { Practice }\end{array}$ & 60 & 12.0 & 42.0 & 83 & 16.6 & 58.0 & 0.732 & 143 & 157 & 31.4 & 41.8 & 218 & 43.6 & 58.2 \\
\hline $\begin{array}{l}\text { Journal of California and } \\
\text { Great Basin } \\
\text { Anthropology }\end{array}$ & 67 & 3.9 & 28.8 & 166 & 9.8 & 71.2 & 0.444 & 233 & 70 & 4.1 & 28.5 & 176 & 10.4 & 71.5 \\
\hline California Archaeology & 24 & 2.7 & 25.5 & 70 & 7.8 & 74.5 & 0.509 & 94 & 59 & 6.6 & 38.8 & 84 & 9.3 & 55.3 \\
\hline \multicolumn{15}{|c|}{ Non-Peer-Reviewed/Reduced-Time-Cost Journals } \\
\hline SAA Record & 289 & 17.0 & 40.8 & 419 & 24.6 & 59.1 & 0.730 & 709 & 166 & 9.8 & 38.6 & 258 & 15.2 & 60.0 \\
\hline $\begin{array}{l}\text { Society for California } \\
\text { Archaeology } \\
\text { Proceedings }\end{array}$ & 211 & 13.2 & 40.8 & 305 & 19.1 & 59.0 & 0.748 & 517 & 140 & 8.8 & 39.5 & 213 & 13.1 & 60.2 \\
\hline Total & 850 & & & 1,592 & & & & 2,445 & 832 & & & 1,690 & & \\
\hline
\end{tabular}



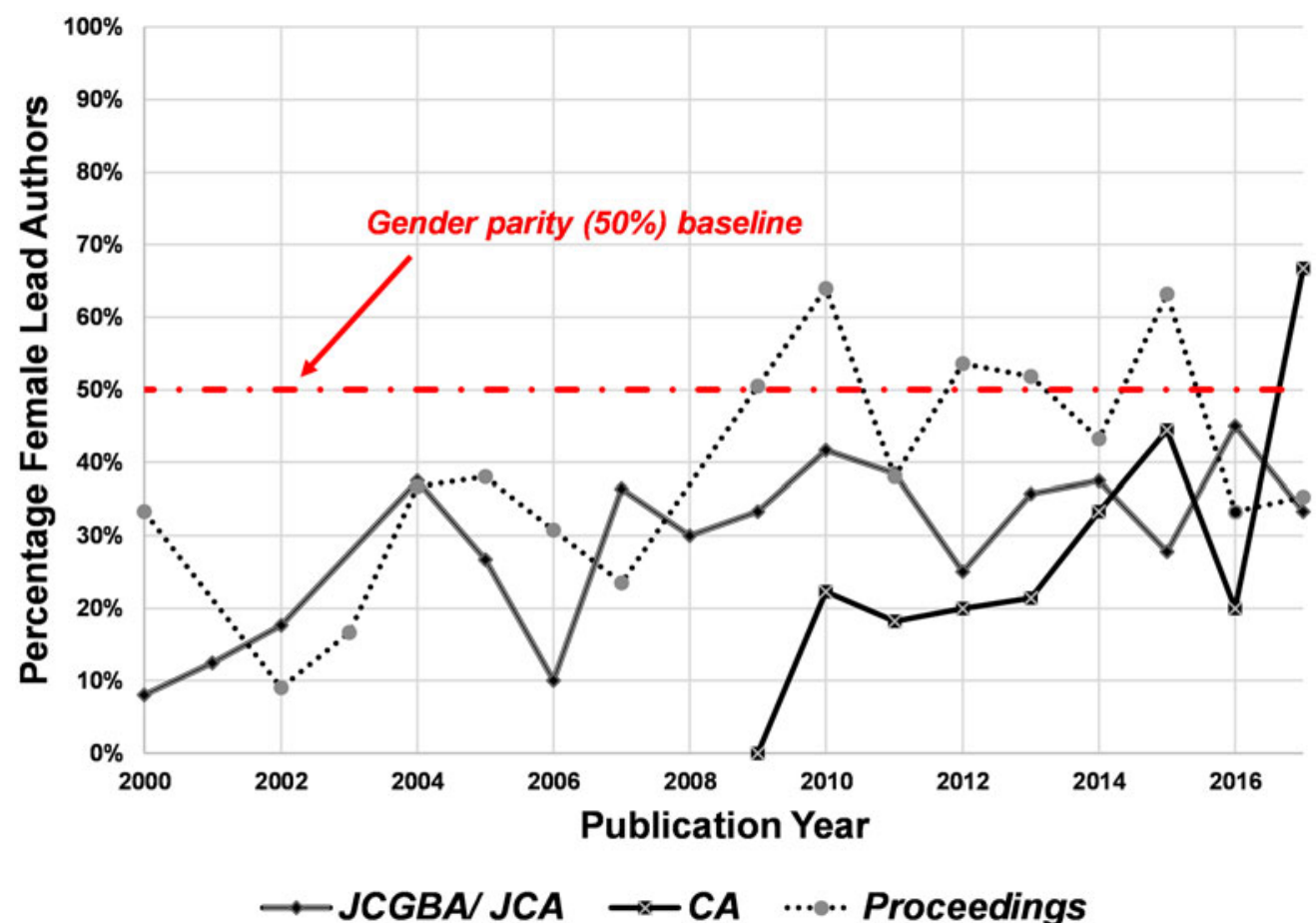

Proceedings

Figure 2. Longitudinal trends in the percentage of women lead authors from three regional archaeology journals published from 2000 to 2017.

women make up $42.0 \%(n=60)$ of first/single authors in $A A P$, they account for a mere $26.6 \%$ ( $n=199$ ) of first/single authors in $A Q$. Similarly, women make up $41.8 \%(n=157)$ of coauthors in $A A P$ and only $24.4 \%(n=240)$ of coauthors in $A Q$. Compared with the peer-reviewed $A Q$, $J C G B A$, and $C A$, considerably more gender equity is revealed in the non-peer-reviewed SAA Record, where women account for $40.8 \%(n=289)$ of primary authors and $38.6 \%(n=166)$ of coauthors versus men.

These figures mirror the representation of women and men in the regional, non-peerreviewed/reduced-time-cost SCA Proceedings, which points to a significant pattern wherein there is greater gender equity among nonrefereed publication venues. Longitudinal trends in the three national venues (Figure 3) indicate that for the period 2000-2017, the SAA Record is the only publication forum to reach or exceed gender parity for women lead authors for more than one year and has consistently had a higher representation of women lead authors compared with $A Q$ and $A A P$. $A Q$ has had the poorest representation of women lead authors from year to year.

Box plot comparisons (Figure 4) demonstrate that among the majority of peer-reviewed/ high-time-cost journals analyzed $(A Q, J C G B A$, $C A$ ), the median distributions of women lead authors are relatively comparable, ranging between $25 \%$ and $30 \%$. In contrast, the nonpeer-reviewed/reduced-time-cost SAA Record and SCA Proceedings, in addition to the peerreviewed $A A P$, exhibit median distributions of just under or over $40 \%$ and come considerably closer to meeting gender parity. The box plots for $A Q$, SAA Record, and $\mathrm{PhD}$ graduates are comparatively short, suggesting that the percentage representations of women are relatively similar from year to year. The box plots for $C A$ and the SCA Proceedings comparatively have the widest range of proportional values (upper and lower whiskers), which suggests greater variability in the representation of women from year to year. 


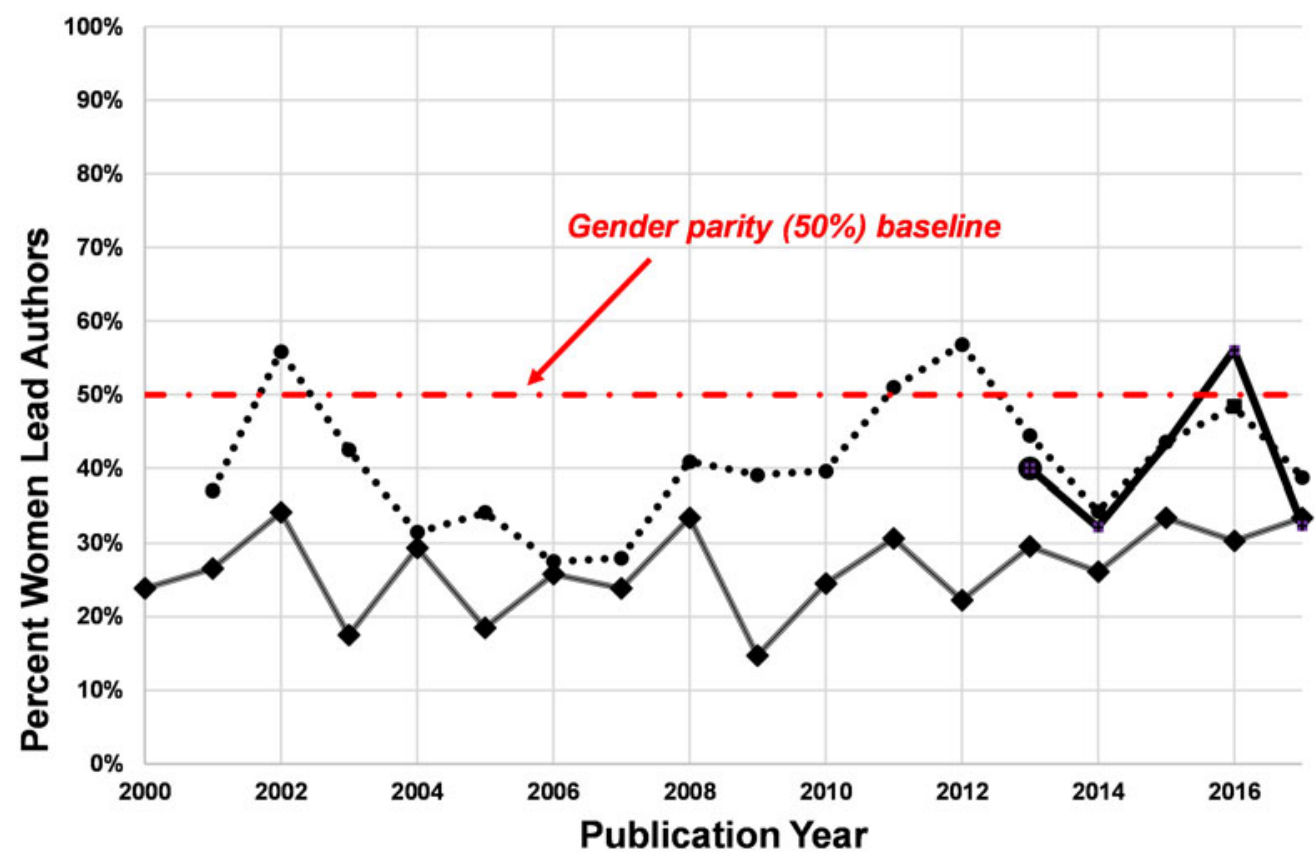

$\multimap$ American Antiquity $\longrightarrow$ Advances Archaeo Practice $\cdots \bullet .$. SAA Record

Figure 3. Longitudinal trends in the percentage of women lead authors from three national archaeology journals published from 2000 to 2017.

\section{Occupational Affiliation Publishing Patterns}

Occupational affiliation patterns for women and men lead authors for the period 2000-2017 indicate that overall, authors from academic settings outnumber those from other professions, including private-sector CRM companies and federal, state, and local agencies. Significantly, however, compliance archaeologists are much better represented in the non-peer-reviewed venues (Figure 5). While these trends are consistent in both regional and national venues, there is considerably more occupational diversity for both peer-reviewed and (especially) non-peer-reviewed/reduced-time-cost journals at the regional level. Across all publication venues, authors with tribe affiliations listed in article bylines are among the most poorly represented.

Among regional peer-reviewed/high-time-cost journals, academics account for an average of $59.3 \% \quad(J C G B A, \quad n=106.5 ; \quad C A, \quad n=13.5)$ of women and $56.4 \%$ (JCGBA, $n=345.5$; CA, $n=35$ ) of men first/single authors in JCGBA and $C A$ combined. Conversely, $35.0 \%(n=111.5)$ of women and 39.7\% ( $n=199)$ of men first/single authors are affiliated with academic institutions in the non-peer-reviewed/reduced-time-cost SCA Proceedings, with compliance archaeologists accounting for roughly half of all authors for both women and men (see Figure 5).

At the national peer-review level, academics account for an average of $82.8 \%(A Q, n=176$; $A A P, n=46)$ of women and $80.0 \%$ ( $A Q, n=$ 438; $A A P, n=66.5)$ of men first/single authors in $A Q$ and $A A P$ combined. In comparison, $64.9 \%(n=187.5)$ of women and 62.9\% $(n=$ 248.5) of men first/single authors are affiliated with academia in the SAA Record. There is considerably more occupational diversity in the nonpeer-reviewed venue compared with the refereed journals, with compliance archaeologists constituting around one-fifth of authors for women and men. Women are slightly better represented among agency-affiliated authors in JCGBA, $C A$, and $A A P$; men are slightly better represented among private-sector/CRM authors in JCGBA, $C A, A Q$, and $A A P$ (see Figure 5). 


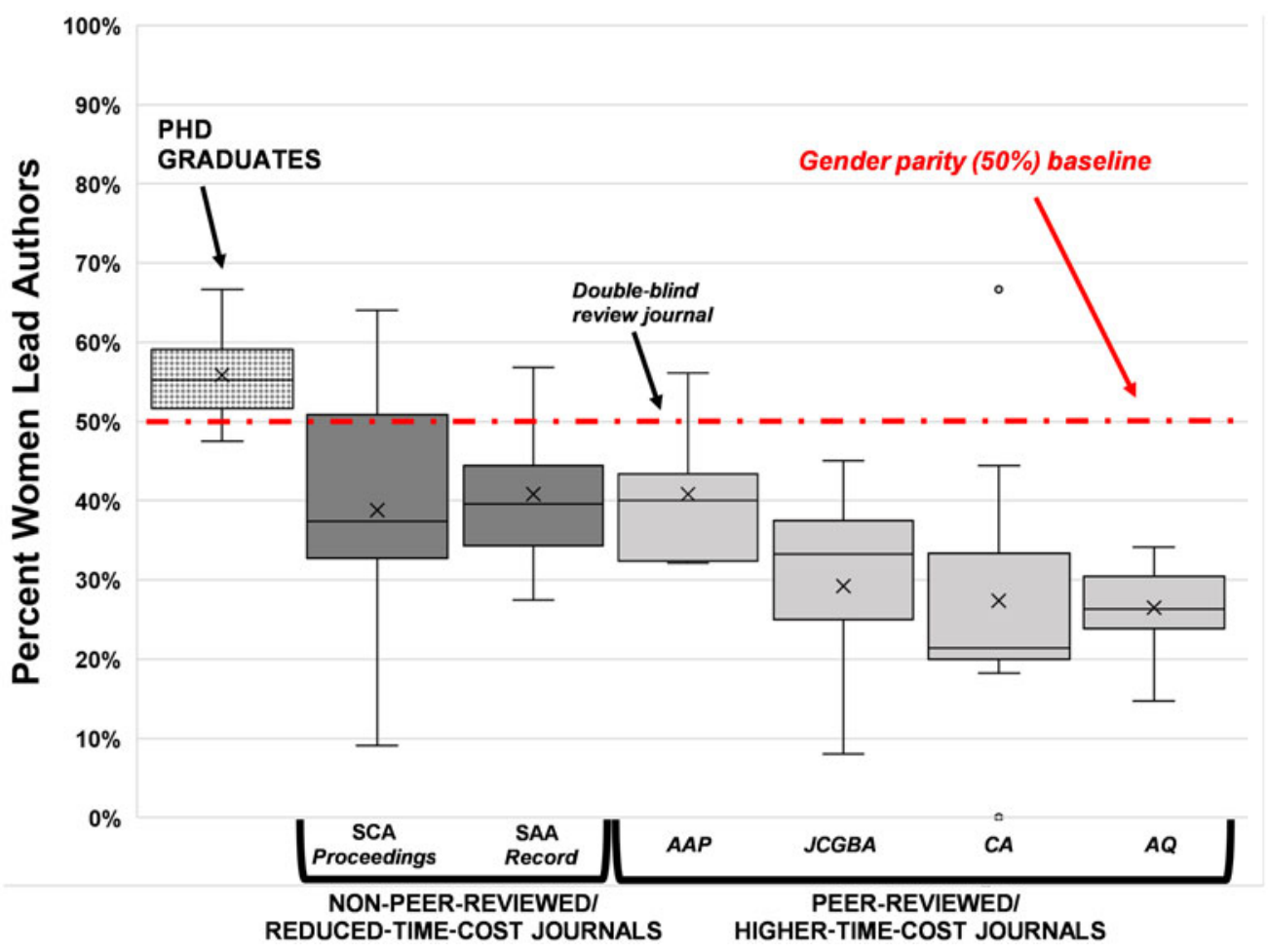

Figure 4. Box and whisker plots representing the median, upper and lower quartiles, and minimum and maximum observations for the percentages of women lead authors in all six of the journals examined in this study for the period 2000-2017, juxtaposed with the percentage of women PhD graduates from 2010 to 2017.

Among all of the journals considered in this study, $A Q$ exhibits the least engagement with compliance archaeologists and the highest engagement with academics. This dominance of academics is particularly true for women, who account for an overwhelming $88.9 \%(n=176)$ of first/single authors, in comparison with the $78.9 \%(n=438)$ of men first/single authors in the same professions. Archaeologists employed with agencies account for a mere $3.0 \%(n=6)$ of women and $4.6 \%(n=25.5)$ of men first/ single authors, while private-sector authors account for only $2.0 \%(n=4)$ of women and $4.6 \%(n=25)$ of men.

\section{Explaining the Publishing Gap}

Recognizing the causes of inequalities in the professional and scientific world is critical to explaining both gender publishing gaps and gaps that exist between academic and extraacademic professionals. Although it is challenging to parse the frameworks for inequities into distinct categories due to their interconnectedness and complexities, we divide the hypotheses and their supporting evidence into six explanatory themes.

\section{Discrimination, (Implicit) Bias, and Microaggressions}

Perhaps the earliest explanations for the barriers to women in professional settings were framed within the context of discrimination and bias, with sexism and androcentrism acting as obstructions that prohibited women from gaining equal footing. These "chilly climate" conditions kept women on the periphery through the processes of stereotyping, devaluation, exclusion, and revictimization (Wylie 1994:67-69). Gero (1983) and Clarke (1993) documented a "ghettoization" of women in archaeology, such that women have often been relegated to clerical roles and the "housework" of research. This "devaluation of women's archaeological labor" 


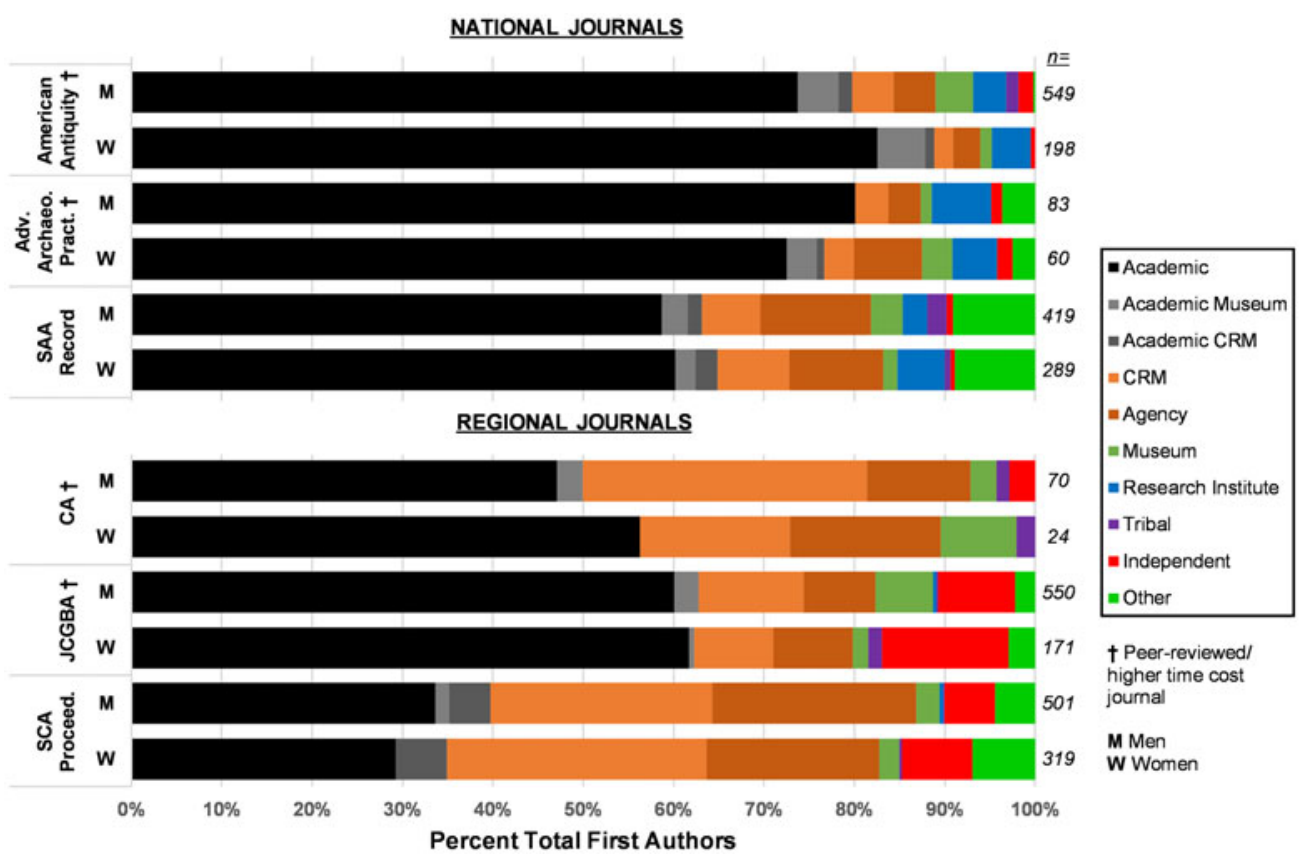

Figure 5. Occupational affiliation of women and men lead authors for three national and three regional journals.

(2002:331) is evidenced in Hutson's study of gendered citation practices in archaeology, wherein it was found that both men and women cited women at rates that were significantly below the rate at which women publish.

While legal status and changing social norms have eliminated many of the blatant forms of sexism over the years, there remain many unconscious forms of power in which sexism is more subtle and embodied and masquerades as benevolence or "paternalistic prejudice" (Baxter 2005:8-9; Geller 2016:162). Contemporary forms of discrimination often manifest in microaggressions, which frequently go unnoticed due to the internalization of acts of sexism as "normal" or "natural." The seemingly negligible effects of microaggressions may be unintentional or well meaning, but they have cumulative effects on women (Baxter 2005:9).

\section{Socialization and Enculturation}

Numerous researchers have documented gendered differences in educational and career choices in STEM fields, which some attribute to socialization, cultural norms, and stereotypes that work together to influence the development of gendered self-beliefs, interests, goals, and values (see Wang and Degol 2013:306, 320). Hidden assumptions about women are imbued in "male-centered discourses" and institutions that shape social and material realities (Bem 1993). The material consequences of gender stereotypes are apparent in the ways that women and men engage in pursuits of upward mobility. Evidence suggests that women are less likely to negotiate for higher pay, while men are more likely to self-promote their accomplishments (Babcock and Laschever 2007). Women have been successful at subverting or "undoing" traditional gender roles in pursuits of success and power, but at the consequence of maintaining environments that are hostile toward them (Powell et al. 2009).

\section{Mentorship}

There is a growing body of literature that highlights the critical importance of proper mentorship for improving equity. Research (MossRacusin et al. 2012) suggests that in some scientific fields, both men and women faculty are less inclined to mentor women than men. Ledin and others (2007) found that in Europe, women 
receive less professional support than men. Lubienski and others (2017) show that men in $\mathrm{PhD}$ programs in STEM fields are more likely to submit and publish scholarly works than their women counterparts, which the authors attribute to gender imbalances in student relationships with their mentors. A recent study by Brown (2018) indicates that among SCA members, women and racial/ethnic minorities are less likely to report an encouraging and inclusive mentor-mentee relationship.

\section{Maternal/Familial Obligations}

Many researchers have observed that maternal and familial obligations disadvantage women by making it more difficult for them to advance academically and fully participate in the workforce. Numerous metaphors have been used to describe this dilemma, including the "second shift" and "double workday," which describe the adverse impacts of gender norms that disproportionately require women, rather than men, to balance family life with the responsibilities of working in a wage labor field (see Wylie 2012:48-49). In the 2003 SAA Members Needs Assessment Survey, more than one-third of women reported that juggling family and a career was the most significant issue they faced professionally (Baxter 2005:8). The disproportionate responsibilities of mothers compared with fathers mean less time available for women to publish and decreases in professional productivity and competitiveness (Ledin et al. 2007:985-986).

Familial obligations impact women differently in each stage of their career. Bardolph and VanDerwarker (2016) find that among Southeastern Archaeological Conference members, parenting/family requirements were a relatively strong limiting factor on the ability of women with $\mathrm{PhDs}$ to publish their research, but this was less true at the graduate student level. Fear of failure influences tenure-track women to delay starting a family until after securing tenure and can discourage women from pursuing tenure-track positions entirely (Mason 2009).

\section{Authorial Choice}

In Rautman's (2012) analysis of online submissions to American Antiquity from 2009 to 2010 , it was found that men published more articles than women but that this was largely the result of men submitting more manuscripts, with male single authors submitting more than twice as many manuscripts as female single authors. Similar observations were made by Beaudry (1994) and Beaudry and White (1994), who found that the rate of manuscript rejection was the same for men and women.

Bardolph (2014:530, 534-535) finds that female lead authors published more articles under male American Antiquity editors than under female editors between 1990 and 2013, which suggests that editor bias does not play a role in gender publishing inequities. The decisions of women to opt out of all or parts of the professional and publishing worlds are partly influenced by the deliberate prioritization of family over work. Stone and McKee found a "culture of motherhood" (2000:80) among undergraduate students, in which women were consciously gearing themselves for lower-level work, dependency on their husbands, and several years at home with their children.

\section{Institutional Barriers}

It has been argued that institutions form a "glass ceiling" that acts as an invisible barrier to the advancement of women and marginalized peoples (see Baxter 2005). In addition to leaky pipelines, women are affected by "revolving door" syndrome, in which they pass in and out of occupations where their levels of compensation and recognition are inferior to those of men (Wylie 1994:66). Such institutionalized barriers have led some to criticize the "illusion" or "tyranny" of choice through the recognition that there are many environmental factors that influence and constrain the decisions of women (see Bernstein 2014).

\section{Discussion}

Our review of the demographic landscape of North American archaeology points to unprecedentedly high levels of participation of women in the discipline. Women now equal or surpass men in the number of PhDs awarded in the United States and make up roughly half of RPA registrants and SAA members (see Figure 1), which points to their strong presence 
in the professional workforce. These optimistic trends might lead some to the erroneous conclusion that archaeology is now a gender-equal enterprise, with women contributing as much as, if not more than, men to the production and dissemination of knowledge. Yet our research and studies by others (summarized above) indicate that this is far from the case. The upper echelons and more prestigious aspects of archaeology - namely, tenure-track faculty positions, leadership roles in the workforce, and peerreviewed publications-have been slow to break free from a tradition in which the discipline is dominated by men.

Consistent with previous research, our results indicate that men continue to constitute the majority of authors in peer-reviewed/ time-intensive publications. The most persistent gender disparities are observed in American Antiquity, which has the highest impact factor (IF) of the journals analyzed and is the flagship journal of the SAA, the largest archaeology society in the world. The historically low levels of participation of women in $A Q$ that we and others (Bardolph 2014; Colwell-Chanthaphonh 2004; Victor and Beaudry 1992) have observed persists today, with women making up a mere $26.6 \%$ of lead authors - a proportion comparable to regional (western North America) journals, where women make up $28.8 \%$ (JCGBA) and $25.5 \%(C A)$ of lead authors (see Figures 2-3; see also Figure 4).

The leaky pipeline effect contributes to the persistent underrepresentation of women in publication output. Throughout the trajectory from college to upper-level career positions (e.g., faculty tenure and compliance-sector leadership positions, such as CEOs, owners of CRM companies, and program managers), there is an attrition of women as they advance along the professional ranks. The loss of women throughout the career pipeline results in fewer women securing positions that offer the time and opportunity to publish. This attrition of women likely contributes to their lower rates of pay in academia and CRM. In addition to the financial consequences of the leaky pipeline, women are adversely impacted by the loss of the professional and social capital that comes with publication and positions of power and prestige.
The occupational affiliation of authors is also important to consider when assessing how publishing trends have evolved with the changing professional landscape of archaeology, as well as for examining the intersections of gender and professional identity. Since the mid-1970s, there has been major growth in compliance archaeology following key legislative developments (see Tushingham et al. 2017:4). Since then, North American archaeology has evolved into a discipline that is now overwhelmingly dominated by compliance professionals. Some might assume that agency and private-sector CRM archaeologists-who conduct the most field archaeology and produce a great corpus of archaeological literature in the form of technical reports-would be increasingly contributing to peer-reviewed journal publications, but this is not the case.

Despite the expansion of compliance archaeology, academics persist in dominating peerreviewed/high-time-cost journals (see Figure 5). This is not surprising considering that publishing is a highly valued and rewarded metric for academics. Professionals in academic settings, particularly at R1 institutions, are pressured to adhere to the "publish or perish" model in order to attain highly coveted and increasingly scarce tenure-track positions, to be granted tenure once these positions have been attained, and to maintain their professional influence. There are far fewer incentives and resources (grant money, labs to facilitate analysis, etc.) as well as less, and often no, time allocated for people in CRM to publish their work. The time and cost constraints of the peer-review process mean that the costs of participating in it often outweigh the benefits for those in non-university settings.

Among the analyzed journals, $A Q$ has the least engagement with compliance archaeologists and the highest engagement with academics, and this is especially true for women lead authors, $88.9 \%$ of whom are academics. Overall, there is less occupational diversity for women authors compared with men. However, there are proportionally more women than men agency authors, while the opposite is true of private-sector authors. Why CRM-employed men publish more than women in the same sector is an important avenue for future work. While 
academics continue to dominate publishing in regional peer-reviewed venues, compliance archaeologists (both men and women) are much better represented in regional journals.

These occupational affiliation trends are likely influenced by varied constraints of publishing that disproportionately disadvantage women who work in both academic and extra-academic settings. All of the obstacles discussed in the "Explaining the Publishing Gap" section above culminate to form institutional barriers, a leaky pipeline, and a difficult-to-penetrate glass ceiling, all of which continue to influence the decisions of women and make upward mobility and professional prosperity challenging for them.

The end result is that women are actively choosing not to publish, likely because of their recognition or internalization of the abovementioned barriers but also likely because of preferences and lifestyle choices that do not involve the prioritization of academia and the professional/social capital that comes with publishing above other aspects of personal and professional satisfaction. Compound these variables with the lack of resources, rewards, and time allocated for women in nonacademic settings to publish, and it is little wonder that women-especially those in nonacademic settings-are publishing in disproportionately lower numbers than their men counterparts. This is especially true with high-IF journals, where the peer-review process can take many months to years to navigate. Differences in the time required to participate in the peer-review process in higher-IF national journals, such as $A Q$, compared with lower-IF regional journals, such as JCGBA and $C A$, might explain why we are seeing considerably higher representations of compliance archaeologists for both women and men in regional compared with national peer-reviewed venues.

Compared with their peer-reviewed counterparts, the nonrefereed/reduced-time-cost SAA Record and SCA Proceedings are the most equitable venues that we analyzed. The national SAA Record has much higher participation from compliance archaeologists and lower percentages of academics, as well as more occupational diversity in general, compared with $A Q$ and $A A P$. Approximately half of all primary authors in the regional SCA Proceedings are agency and private-sector CRM archaeologists, which amounts to the greatest representation of compliance archaeologists out of all of the journals analyzed.

With regard to gender, we see noticeably higher representations of women in the SAA Record and SCA Proceedings, with women making up $40.8 \%$ of authors in both journals from 2000 to 2017. The exception to this trend occurs with the peer-reviewed $A A P$, where women account for almost half of primary authors (see Figure 4). AAP premiered recently, in 2013, so it is difficult to determine whether this reflects an enduring pattern within the journal, and it is important to note that women's participation exceeded $50 \%$ in only one of the five years analyzed. Thus, is it possible that the results are skewed due to an outlier, but it is also possible that the gender parity reflects the scope of $A A P$ as a journal that appeals to agencies and CRM companies, which are rich with women. While our data do not permit us to explore whether double-blind versus single-blind reviews were a factor in the representativeness of women and nonacademics in publishing output, it is also interesting to note that $A A P$ is the only peer-reviewed journal among those analyzed to practice a double-blind review process for the period of study. This issue warrants further consideration.

Based on these results, we argue that nonpeer-reviewed/reduced-time-cost forums such as the SAA Record and SCA Proceedings provide an important pathway to multivocality in North American archaeology for both women and compliance professionals. To limit the discourses in archaeology to predominately men and academics is problematic because it prevents pluralistic possibilities and inhibits the multitude of voices and knowledge that could, and should, be contributing to narratives of the human past. Archaeology has an ethical obligation to integrate the silenced voices with the groups that currently dominate discourse (see Conkey and Gero 1997:430; Kehoe 1992:23). These silenced voices include not just women as a monolithic group but also women who exist outside of the white, cisgender, and heteronormative demographics that continue to prevail in archaeology. They also include Indigenous people and those 
with tribal affiliations-who, we have shown, are among the most poorly represented affiliation category across all of the journals analyzed-as well as agency and private-sector CRM professionals. The incorporation of these diverse perspectives will help to combat forms of epistemic injustice and the "distributive unfairness in respect to epistemic goods such as information or education" (Fricker 2007:1).

Some of the most significant work in archaeology today is conducted by CRM professionals, yet much of this work remains hidden from the broader archaeology community, let alone the public (Lipe 2009:50). Indeed, dissemination remains a challenge in archaeology, and as practitioners of an enterprise that relies on publicly funded undertakings to sustain itself, archaeologists have an ethical obligation to improve accessibility to their research and to convey the importance of their work to the public (see Lipe 2009). Compliance archaeology is made up of diverse stakeholders, including tribes, project proponents, clients, grant agencies, and the public_-all of whom maintain a vested interest and role in the cultural preservation process.

Non-peer-reviewed/reduced-time-cost journals are a useful mechanism for disseminating work to these diverse stakeholders in an expedient and widely accessible manner. Put another way, publishing in such venues can be a timeminimizing strategy, one that is logical to pursue for those short on time and resources to navigate the peer-review process. These venues serve to promote and legitimize the work of individuals who might otherwise find publishing to be inaccessible. As such, they help to democratize archaeology and provide a forum for conveying information about the parts of the archaeological record that are considerably important to the stakeholders of CRM. With the increase in women and professional diversity, nonrefereed venues may create a space for different and sometimes competing perspectives and theories, which is important for cultivating new and better insights on the world (see McGuire 1992:7).

To be clear, our promotion of non-peerreviewed journals is not to say that they should serve as a replacement for peer-reviewed publications or that they are not vulnerable to low-quality work. Indeed, the peer-review process remains effective at ensuring that scholarly work is scrutinized by experts and held to necessary standards and thus has an important place in the sciences. Our ultimate goal should be to improve the peer-review process and close the publishing gap in archaeology by actively encouraging more women, compliance archaeologists, and other peripheral groups to contribute to it. But until we break down the barriers that prohibit certain people from participating in the refereed publishing process, we believe that non-peer-reviewed journals present a publication strategy with fewer time constraints for a wider authorship and thus may be one vehicle that helps archaeology "to hear the muted groups" (Kehoe 1992:28) and to make the discipline more equitable and reflective of the community in its entirety.

\section{Toward a More Multivocal Archaeology}

Ensuring a more equitable and multivocal archaeology requires a multiscalar plan of action that integrates both top-down and bottom-up approaches. Ultimately, progress will require a dissolution of the structural, institutional, and ideological barriers that impede women, nonacademics, and marginalized groups, including people of color and LGBTQ+ people, from being strong participants in publishing. At the broader cultural and societal levels, changes that will help to promote greater balance in the professional/ scientific worlds include ensuring equal distribution of parenting and household workloads (rather than adhering to the traditional placement of the bulk of the family burden on mothers), providing adequate paid family leave for all parents, discouraging biases and harmful gender stereotypes that impede the progress of women/girls and marginalized groups in education and the workplace, and cultivating healthy self-confidence and leadership skills among women/girls and marginalized groups in an effort to promote their educational and professional advancement.

While these issues are vast and beyond the scope of what the discipline alone can address, we offer several approaches for improving equity and dissemination that may be pursued by archaeologists. In particular, departments, 
professional societies, journal editorial boards, faculty mentors, and professional supervisors may develop policies and implement task forces that address equity concerns when none are already in place. This is not to say that authorial choice is not critical to improving publishing equity-indeed, individual choice is vital, and ultimately women and compliance professionals are the ones who need to write papers and ferry them through the review process-but the discipline can work toward facilitating a favorable climate and realistic opportunities for these individuals to have the time, motivation, and opportunities to do so.

\section{Increased Opportunities/Leadership Positions for Women and Marginalized Peoples}

As detailed in this article, there are certain occupations that offer more time and support for publishing activities. There needs to be a greater push for better inclusion of women and historically underrepresented groups in tenure-track faculty positions, managerial and director roles, CRM company ownership, and other jobs that afford them with time opportunities/conditions to publish and access other forms of professional and economic capital.

\section{Mentorship}

Vertical (junior-senior) and horizontal (peerbased) mentors play a vital role in the movement toward a more inclusive archaeology (see Baxter et al. 2008). We encourage faculty advisers and job supervisors to be cognizant of, and combat, biases that may impact students and junior staff and to cultivate an inclusive environment while providing equal opportunities for students of color and women, LGBTQ+ people, and other underrepresented students to author/coauthor papers. Successful mentorship effectively integrates the personal and professional spheres of a student's life (Surface-Evans and Jackson 2012:21), and greater gender parity at the faculty level will help to facilitate such integrated forms of mentorship for women graduate students (Brown 2018).

\section{Double-Blind Review}

There is a considerable body of literature that explores equity in journals that practice double- versus single-blind review processes, with research suggesting that there may be more equitability in double-blind journals. While Bardolph (2014) and others have indicated that gender disparities in archaeology publishing are not the result of editorial or reviewer bias, we know of no studies that address equity and blind peerreview processes in North American archaeology and believe that this would be a useful avenue of exploration for future research. Moreover, journals should track self-reported identity data for the purposes of assessing demographic diversity and to prevent improper gender attribution.

\section{Encouraging the Dissemination of Gray Literature}

In an effort to ensure that there is greater public and professional engagement with gray literature, which is a major forum through which compliance archaeologists communicate their work, we encourage agency and CRM professionals to submit nonconfidential technical reports and other nonpublished works to online digital repositories in order to increase their visibility and potential for wider dissemination. Existing repositories, such as the Digital Archaeological Record and the Grey Literature Network Service, are excellent venues that exist for such purposes. Professional societies and organizations, such as the SAA and RPA, might also consider creating regionally specific online resources in order to facilitate such engagement. Moreover, we encourage policy changes among major publication venues that either make it difficult for authors to cite unpublished works or prohibit it altogether in order to ensure more equitability for authors of gray literature and to encourage greater academic engagement with nonpublished works.

\section{Multivocal Publications-Realistic \\ Opportunities, Alternative Mitigations}

Based on the greater representation of compliance archaeologists in non-peer-reviewed venues detailed in the previous sections, we argue that such forums can and do provide more realistic opportunities for compliance archaeologists to disseminate their work. Encouraging and incentivizing more compliance professionals to publish will likely require more employers to 
provide rewards and time to publish, as well as integrating reduced-time-cost (namely, nonpeer-reviewed) publishing as a component of the scope of work in contracts. Buy-ins from agencies, clients, and project proponents can occur by demonstrating that low-time-cost publishing is an ideal method of using public dollars wisely. Most agencies have policies that promote or mandate public education and outreach, and in some cases, contractors are required to present the results of their work in various forums as part of the mitigation process. In these cases, non-peer-reviewed publications may serve as an alternative form of mitigation or as a welcome addition to the types of public education (brochures, presentations, web pages, etc.) that are already in place. CRM companies could benefit from using their publishing history as a selling point during the bidding process and when responding to a Request for Qualifications/ Request for Proposals, which may make them more competitive in the eyes of agencies and clients.

We see the SCA Proceedings as an ideal (open-access, nonrefereed journal) model for low-cost (reduced-time-investment) publishing that can be scheduled into CRM jobs and is freely disseminated; Proceedings articles are published annually, have no space limitations, and can be scheduled in a timely manner (after authors present at the SCA annual meeting), and since 2009, all content is freely available to the public at no cost (Tushingham et al. 2017).

\section{Conclusion}

Although roughly half of archaeologists in North America are women, and $90 \%$ are agency and private-sector CRM professionals (Sebastian 2009:7), our results indicate that these people are some of the least likely to publish in peerreviewed/high-time-cost journals. Despite the varied backgrounds of archaeologists, most who publish in these places are academic men. For women, the leaky pipeline effect, in combination with a suite of academic, societal, and individual factors, affects their abilities and decisions to publish in high-time-cost journals, while for agency and private-sector/CRM archaeologists, the professional lack of time, resources, and incentives to publish tempers decisions of whether and where to publish. Rather than encouraging them to disseminate their research in peer-reviewed forums, the cost-benefit realities of publishing for women and compliance archaeologists influence many to pursue alternative strategies of communicating their worknamely, through non-peer-reviewed/reducedtime-cost publications.

North American archaeology is a dynamic field that has evolved considerably, both politically and professionally, over the last several decades. For the discipline to maintain its relevance to its many stakeholders, minimize epistemic injustices (see Fricker 2007), and uphold the core values of anthropology, it is important that it persistently strives for greater inclusivity and diversity. Critical to the move toward a more multivocal archaeology is the active promotion and participation of women, compliance archaeologists, and other groups that have historically remained on the periphery of knowledge dissemination, particularly in prominent journal publications. Non-peer-reviewed/reduced-time-cost venues help to facilitate multivocality, but ultimately, systemic and individualized barriers need to be addressed in order to ensure a more equitable future. It is our hope that studies such as our own will help to aid this process and that the future will hold a more all-encompassing archaeology.

Acknowledgments. We thank the Society for California Archaeology and Register of Professional Archaeologists for providing membership and registration lists and historical information. We are grateful to the National Science Foundation for supplying Figure $1 \mathrm{PhD}$ data, William Lipe for offering valuable feedback, and Alexis Evans for compiling data on Register of Professional Archaeologists registrations. Last, we are appreciative of the thoughtful feedback from the reviewers of this article, which helped to improve it.

Data Availability Statement. A Microsoft Excel spreadsheet containing data on the gender and occupational affiliation of authors in American Antiquity, Advances in Archaeological Practice, SAA Archaeological Record, the Journal of California and Great Basin Anthropology, California Archaeology, and SCA Proceedings is available from Tiffany J. Fulkerson and Shannon Tushingham at Washington State University, Pullman.

Supplemental Materials. For supplementary material accompanying this article, visit https://doi.org/10.1017/aaq. 2019.35 
Supplemental Text 1. Journal Summaries.

Supplemental Text 2. Journal Sections Analyzed.

Supplemental Text 3. Gender Categorization Methods.

Supplemental Text 4. Occupational Affiliation Categories.

Supplemental Table 1. Summary of Annual Gender Authorship Data for American Antiquity (AQ), Advances in Archaeological Practice (AAP), SAA Archaeological Record (SAA Record), the Journal of California and Great Basin Anthropology (JCGBA), California Archaeology (CA), and SCA Proceedings from 2000 to 2017.

\section{References Cited}

Alper, Joe

1993 The Pipeline Is Leaking Women All the Way Along. Science 260(5106):409-411.

Anderson, David G.

2018 Using CRM Data for "Big Picture" Research. In New Perspectives in Cultural Resource Management, edited by Francis P. McManamon, pp. 197-212. Routledge, New York

Association Research

20052005 Salary Survey Conducted for the Society for American Archaeology in Cooperation with the Society for History Archaeology, July. Electronic document, http://www.saa.org/Portals/0/SAA/membership/survey/ full.pdf, accessed August 8, 2018.

Babcock, Linda, and Sara Laschever

2007 Women Don't Ask: The High Cost of Avoiding Negotiation-and Positive Strategies for Change. Bantam Bell, New York

Bardolph, Dana N.

2014 A Critical Evaluation of Recent Gendered Publishing Trends in American Archaeology. American Antiquity 79:522-540.

2018 Controlling the Narrative: A Comparative Examination of Gendered Publishing Trends in the SCA and Beyond. California Archaeology 10:159-186.

Bardolph, Dana N., and Amber M. VanDerwarker

2016 Sociopolitics in Southeastern Archaeology: The Role of Gender in Scholarly Authorship. Southeastern Archaeology 35:175-193.

Baxter, Jane Eva

2005 Gender Perceptions of Archaeology: A Perspective from the SAA Member Needs Assessment Survey. SAA Archaeological Record 5(4):7-9.

Baxter, Jane Eva, Tracie Mayfield, Jodie O'Gorman, Jane Peterson, and Tammy Stone

2008 Mentoring Strategies for Women in Archaeology: A Report of the 2008 COSWA Working Group. SAA Archaeological Record 8(4):15-18.

Beaudry, Mary C.

1994 Women Historical Archaeologists: Who's Counting? In Equity Issues for Women in Archaeology, edited by Margaret C. Nelson, Sarah M. Nelson, and Alison Wylie, pp. 225-228. Archeological Papers No. 5. American Anthropological Association, Washington, DC.

Beaudry, Mary C., and Jacquelyn White

1994 Cowgirls with the Blues? A Study of Women's Publication and the Citation of Women's Work in Historical Archaeology. In Women in Archaeology, edited by Cheryl Claassen, pp. 138-158. University of Pennsylvania Press, Philadelphia.
Bem, Sandra Lipsitz

1993 The Lenses of Gender: Transforming the Debate on Sexual Inequality. Yale University Press, New Haven, Connecticut.

Bernstein, Rachel

2014 Is Academic Science Sexist? Science, November 6. Electronic document, http://www.sciencemag.org/ careers/2014/11/academic-science-sexist, accessed March 3, 2017.

Brown, Kaitlin M.

2018 Gender, Race, and Mentorship: A Perspective from California Archaeology. California Archaeology 10:187-210.

Burkholder, Jo Ellen

2006 Doing It for Ourselves: Women and Participation in the SAA Annual Meetings. SAA Archaeological Record 6(2):27-31.

Chronicle of Higher Education

2016 Chronicle Data. Chronicle of Higher Education. Electronic document, https://www.data.chronicle.com, accessed September 11, 2018.

Claassen, Cheryl, Michael O'Neal, Tamara Wilson, Elizabeth Arnold, and Brent Lansdell

1999 Hearing and Reading Southeastern Archaeology: A Review of the Annual Meeting of SEAC from 19831995 and the Journal Southeastern Archaeology. Southeastern Archaeology 18:85-97.

Clancy, Kathryn B. H., Robin G. Nelson, Julienne N. Rutherford, and Katie Hinde

2014 Survey of Academic Field Experiences (SAFE): Trainees Report Harassment and Assault. PLOS ONE 9 (7):e102172.

Clarke, Anne

1993 Cultural Resource Management (CRM) as Archaeological Housework: Confining Women to the Ghetto of Management. In Women in Archaeology: A Feminist Critique, edited by Hilary du Cros and Laurajane Smith, pp. 191-194. Occasional Papers in Prehistory, Series No. 23. Department of Prehistory, Research School of Pacific and Asian Studies, Australian National University, Canberra.

Colwell-Chanthaphonh, Chip

2004 Publishing the Past: Gender and Patterns of Authorship in Academic and Public Archaeology Journals. Graduate Journal of Social Science 1(1):117-143.

Conkey, Margaret W.

2003 Has Feminism Changed Archaeology? Signs 28:867-880.

Conkey, Margaret W., and Joan M. Gero

1997 Programme to Practice: Gender and Feminism in Archaeology. Annual Review of Anthropology 26:411437.

Conkey, Margaret W., and Janet D. Spector

1984 Archaeology and the Study of Gender. In Advances in Archaeological Method and Theory, Vol. 7, edited by Michael B. Schiffer, pp. 1-38. Academic Press, New York.

Fawcett, Clare, Junko Habu, and John M. Matsunaga

2008 Introduction: Evaluating Multiple Narratives: Beyond Nationalistic, Colonialist, Imperialist Archaeologies. In Evaluating Multiple Narratives: Beyond Nationalist, Colonialist, Imperialist Archaeologies, edited by Junko Habu and John M. Matsunaga, pp. 1-11. Springer, New York.

Finkelstein, Martin J., Valerie Martin Conley, and Jack H. Schuster 
2016 Taking the Measure of Faculty Diversity. TIAA Institute, April. Electronic document, https://www.tiaainstitute. org/sites/default/files/presentations/2017-02/taking_the_ measure_of_faculty_diversity.pdf, accessed June 3, 2018.

Fricker, Miranda

2007 Epistemic Injustice: Power and the Ethics of Knowledge. Oxford University Press, New York.

Fulkerson, Tiffany J., and Shannon Tushingham

2019 Writing and Publishing in Anthropology: Voices, Insights, and Disciplinary Trends. In Why Don't We Write More? Essays on Writing and Publishing Anthropological Research, edited by Darby C. Stapp, Julia G. Longenecker, Tiffany J. Fulkerson, and Shannon Tushingham, pp. 181-188. Journal of Northwest Anthropology special reprint, Northwest Anthropology, Richland, Washington.

Geller, Pamela L.

2016 This Is Not a Manifesto: Archaeology and Feminism. In Meta-philosophical Reflection on Feminist Philosophies of Science, Vol. 317, edited by Maria C. Amoretti and Nicla Vassallo, pp. 151-170. Springer International, Basel, Switzerland.

Gero, Joan M.

1983 Gender Bias in Archaeology: A Cross-Cultural Perspective. In The Socio-politics of Archaeology, edited by Joan M. Gero, David M. Lacy, and Michael L. Blakey, pp. 51-57. Department of Anthropology Research Report No. 23. University of Massachusetts, Amherst.

1985 Socio-politics of Archaeology and the Woman-atHome Ideology. American Antiquity 50:342-350.

Goldstein, Lynne, Barbara J. Mills, Sarah Herr, Jo Ellen Burkholder, Leslie Aiello, and Christopher Thornton

2018 Why Do Fewer Women than Men Apply for Grants after Their PhDs? American Antiquity 83:367-386.

Harlan, Mark E.

2009 Archaeology's Grey Literature and Professional Review. Grey Journal 5(2):83-88.

Heath-Stout, Laura

2017 An Intersectional Study of Authorship and Citation in American Antiquity, Latin American Antiquity, and Advances in Archaeological Practice. Paper presented at the 82nd Annual Meeting of the Society for American Archaeology, Vancouver, British Columbia, Canada.

Hodder, Ian

2004 Who to Listen To? Integrating Many Voices in an Archaeological Project. In Archaeology beyond Dialogue, pp. 23-28. University of Utah Press, Salt Lake City.

Hutson, Scott R.

1998 Institutional and Gender Effects on Academic Hiring Practices. SAA Bulletin 16(4):19-21.

2002 Gendered Citation Practices in American Antiquity and Other Archaeology Journals. American Antiquity 67:331-342.

Kehoe, Alice B.

1992 The Muted Class: Unshackling Tradition. In Exploring Gender through Archaeology: Selected Papers from the 1991 Boone Conference, edited by Cheryl Claassen, pp. 23-31. Monographs in World Archaeology No. 11. Prehistory Press, Madison, Wisconsin.

Kramer, Carol, and Miriam Stark

1988 The Status of Women in Archaeology. Anthropology Newsletter 29(9):11-12.

Ledin, Anna, Lutz Bornmann, Frank Gannon, and Gerlind Wallon

2007 A Persistent Problem: Traditional Gender Roles
Hold Back Female Scientists. EMBO Reports 8:982987.

Lipe, William D.

2009 Archaeological Values and Resource Management. In Archaeology and Cultural Resource Management: Visions for the Future, edited by Lynne Sebastian and William D. Lipe, pp. 41-64. School for Advanced Research Press, Santa Fe, New Mexico.

Lubienski, Sarah Theule, Emily K. Miller, and Evthokia Stephanie Saclarides

2017 Sex Differences in Doctoral Student Publication Rates. Educational Research 47(1):76-81.

McGuire, Randall $\mathrm{H}$.

1992 A Marxist Archaeology. Academic Press, San Diego, California.

Mason, Mary Ann

2009 Is Tenure a Trap for Women? Chronicle of Higher Education, April 22. Electronic document, https://www. chronicle.com/article/Is-Tenure-a-Trap-for-Women-/44814, accessed March 4, 2017.

Miller, David I., and Jonathan Wai

2015 The Bachelor's to Ph.D. STEM Pipeline No Longer Leaks More Women than Men: A 30-Year Analysis. Frontiers in Psychology 6. DOI:10.3389/fpsyg.2015. 00037, accessed July 9, 2018.

Moser, Stephanie

2007 On Disciplinary Culture: Archaeology as Fieldwork and Its Gendered Associations. Journal of Archaeological Method and Theory 14:235-263.

Moss-Racusin, Corrine A., John F. Dovidio, Victoria L. Brescoll, Mark J. Graham, and Jo Handelsman

2012 Science Faculty's Subtle Gender Biases Favor Male Students. PNAS 109(41):16474-16479.

Niquette, Garland F.

2017 The Evolution of the Register. Manuscript on file, Register of Professional Archaeologists, Baltimore, Maryland.

Peterson's

2016 Graduate Programs in the Humanities, Arts and Social Sciences 2016. Peterson's, Albany, New York.

Powell, Abigail, Barbara Bagilhole, and Andrew Dainty

2009 How Women Engineers Do and Undo Gender: Consequences for Gender Equality. Gender, Work and Organization 16:411-428.

Radde, Hugh D.

2018 Sexual Harassment among California Archaeologists: Results of the Gender Equity and Sexual Harassment Survey. California Archaeology 10:231-256.

Rautman, Alison E.

2012 Who Gets Published in American Antiquity? SAA Archaeological Record 12(2):25-26, 30.

Sebastian, Lynne

2009 The Future of CRM Archaeology. In Archaeology and Cultural Resource Management: Visions for the Future, edited by Lynne Sebastian and William D. Lipe, pp. 3-18. School for Advanced Research Press, Santa Fe, New Mexico.

Seymour, Deni J.

2010a In the Trenches around the Ivory Tower: Introduction to Black-and-White Issues about the Grey Literature. Archaeologies 6:226-232.

2010b Sanctioned Inequity and Accessibility Issues in the Grey Literature in the United States. Archaeologies 6:233-269.

Speakman, Robert J., Carla S. Hadden, Matthew H. Colvin, Justin Cramb, K. C. Jones, Travis W. Jones, 
Isabelle Lulewicz, Katharine G. Napora, Katherine L. Reinberger, Brandon T. Ritchison, Alexandra R. Edwards, and Victor D. Thompson018 Market Share and Recent Hiring Trends in Anthropology Faculty Positions. PLoS ONE 13(9):e0202528.

Stark, Barbara L., Katherine A. Spielmann, Brenda Shears, and Michael Ohnersorgen

1997 The Gender Effect on Editorial Boards and in Academia. SAA Bulletin 15(4):6-9.

Stone, Linda, and Nancy P. McKee

2000 Gendered Futures: Student Visions of Career and Family on a College Campus. Anthropology and Education Quarterly 31:67-89.

Surface-Evans, Sarah L., and Misty Jackson

2012 Feminine Voices in Archaeology: Promoting Community, Collaboration, and Mentoring. SAA Archaeological Record 12(1):19-22.

Tushingham, Shannon, Tiffany Fulkerson, and Katheryn Hill 2017 The Peer Review Gap: A Longitudinal Case Study of Gendered Publishing and Occupational Patterns in a Female-Rich Discipline, Western North America (1974-2016). PLoS ONE 12(11):e0188403.

VanDerwarker, Amber M., Kaitlin M. Brown, Toni Gonzalez, and Hugh Radde

2018 The UCSB Gender Equity Project: Taking Stock of Mentorship, Equity, and Harassment in California Archaeology Through Qualitative Survey Data. California Archaeology 10:131-158.

Victor, Katherine L., and Mary C. Beaudry

1992 Women's Participation in American Prehistoric and Historic Archaeology: A Comparative Look at the Journals American Antiquity and Historical Archaeology. In Exploring Gender through Archaeology: Selected Papers from the 1991 Boone Conference, edited by Cheryl Claassen, pp. 11-22. Monographs in World Archaeology No. 11. Prehistory Press, Madison, Wisconsin.

Wang, Ming-Te, and Jessica Degol

2013 Motivational Pathways to STEM Career Choices:
Using Expectancy-Value Perspective to Understand Individual and Gender Differences in STEM Fields. Developmental Review 33:304-340.

Weeden, Kim A., Sarah Thébaud, and Dafna Gelbgiser

2017 Degrees of Difference: Gender Segregation of U.S. Doctorates by Field and Program Prestige. Sociological Science 4:123-150.

Wylie, Alison

1992 The Interplay of Evidential Constraints and Political Interests: Recent Archaeological Research on Gender. American Antiquity 57:15-35.

1994 The Trouble with Numbers: Workplace Climate Issues in Archaeology. In Equity Issues for Women in Archaeology, edited by Margaret C. Nelson, Sarah M. Nelson, and Alison Wylie, pp. 65-71. Archeological Papers No. 5. American Anthropological Association, Washington, DC.

1997 The Engendering of Archaeology: Refiguring Feminist Science Studies. Osiris 12:80-99.

2012 Feminist Philosophy of Science: Standpoint Matters. Proceedings and Addresses of the American Philosophical Association 86(2):47-76.

Yellen, John

1983 Women, Archaeology and the National Science Foundation. In The Socio-politics of Archaeology, edited by Joan M. Gero, David M. Lacy, and Michael L. Blakey, pp. 59-65. Department of Anthropology Research Report No. 23. University of Massachusetts, Amherst.

Zeder, Melinda A.

1997a The American Archaeologist: A Profile. AltaMira, Walnut Creek, California.

1997b The American Archaeologist: Results of the 1994 SAA Census. SAA Bulletin 15(2):12-17.

Submitted November 19, 2018; Revised March 30, 2019;

Accepted March 30, 2019 